What the scientist has to say

Arthur Kornberg

Storm Over Biology: Essays on Science, Sentiment, and Public Policy. By Bernard D. Davis. Prometheus, Buffalo, New York: 1986. Pp.324. \$22.95.

SCIENTISTS make poor politicians. They have been self-selected for their interest in things rather than people, and they are generally neither literary nor articulate. They form societies to communicate with one another about their arcane findings but, with some exceptions, they are distinguished from most other professional groups by their social isolation and political innocence.

Were the responsibility of scientists limited to progress in such areas as chess or hieroglyphics, their ineptitude in worldly matters might be tolerated with whimsical affection. But the affairs of government and business, our everyday lives and future depend crucially on science and its technological applications. Must we then rely solely on salesmen, actors and lawyers to make the difficult decisions that require informed judgement about scientific questions? What are we to do?

To compound the problem, the media seem to be entranced by the pronouncements of those who lack scientific knowledge and of a few scientists who have ideological biases and crave publicity. The brushfire controversies over drugs, toxic wastes and genetic engineering have coalesced into wider conflagrations of hostility to all technological, scientific and intellectual effort. Legitimate concern about biological warfare has turned into all-out warfare against biology.

Fortunately there are a few informed and responsible scientists who speak out and write clearly on issues involving biology and society. One such is Bernard D. Davis. In Storm Over Biology he has collected together 44 essays and shorter pieces on "science, sentiment and public policy". All but one of these have appeared in print in the past ten years, many in obscure places. Trained as a physician, now a scientist with a distinguished record of administration and of research in biochemistry and microbiology, Davis has intimate knowledge of the difficult issues that he has chosen to confront.

Among the matters that get attention are sociobiology, affirmative action in medical schools and genetic engineering. The common theme underlying all of these topics is the need to build on reality and protect science from politicization by the left or the right. In particular, on the perennial debate over biological versus

fighter for liberal causes and the first department chairman in the history of Harvard University to appoint a black to tenure - cannot be accused of insensitivity to the need for social justice. Yet his editorial in the New England Journal of Medicine, arguing for reasonable stretching in increasing the opportunities for minority candidates, was presented by the news media as a racist attack, and he was vilified by many colleagues at Harvard Medical School in the hysterical atmosphere that swept through academic faculties during the late 1960 s and early 1970 s.

I sometimes wished for the dashes of humour that lace Davis's lectures, but the issues in these essays are really serious business. In his foreword, Edward Shils suggests that scientists generally underestimate the depth of the current antiscience movement, and he makes it clear why this important set of statements by Davis will reward the attention of the general public as well as scientists.

Arthur Kornberg is a Professor in the Department of Biochemistry, Stanford University
School of Medicine, Stanford, California 94305, USA.

\section{Sigmund meets Charles}

\section{John R. Durant}

The Problem of Altruism: FreudianDarwinian Solutions. By C. R. Badcock. Basil Blackwell: 1986. Pp. 206. £14.95, $\$ 24.95$.

BoTH natural and social scientists regard Freud's psychoanalytic theories as a somewhat baroque construction of overelaborate and largely untestable speculations. The Problem of Altruism is dedicated to the task of restoring them to their rightful place in the scientific sun. Christopher Badcock is a social scientist who regards conventional social theories of all sorts as hopelessly inadequate to their task. These theories, he argues, being committed to various forms of "holism" and "cultural determinism", are all involved in the futile attempt to explain one social phenomenon in terms of another. What is needed instead, he suggests, is a reconstruction of sociological theory on more reductionist and individualist foundations, and he attempts to lay these foundations by combining psychoanalysis with darwinian social theory, or human sociobiology.

At first sight, this seems a most unpromising strategy. Not only does human sociobiology have a reputation of its own for over-elaboration and untestability, but also it appears to be quite distinct in its approach to the explanation of behaviour. Where freudian theory deals with psychological entities such as the conscious, the pre-conscious and the unconscious minds, and with psychological processes such as projection, regression and repression, darwinian social theory deals with biological entities such as genotypes and phenotypes, and with biological processes such as kin selection and reciprocal altruism. Where is the room for marriage between these two?

Badcock's central argument is that the place where psychoanalysis and sociobiology meet is in the field of "dynamic psychology". For example, the American sociobiologist Robert Trivers has analysed the relationship between parents and their offspring in terms of psychological conflict; and he has debated the possible adaptive advantages of the unconscious mind. In each case, a recent sociobiological analysis appears to mirror an older, psychoanalytic view. Modern darwinists, Badcock suggests, are busy rediscovering and vindicating Freud.

Badcock builds his case for the rehabilitation of Freud around the central theoretical problem of sociobiology, namely altruism. Sociobiologists admit only two major mechanisms for the evolution of behaviour which raises the reproductive fitness of another individual at the expense of that of the actor: reciprocity, and kin selection. Reciprocity, he suggests, may have become an important element in human social behaviour with the development of cooperative big-game hunting; and it may have led to the rapid evolution 